\title{
EL HABLA ACTUAL DE LOS ESPAÑOLES
}

\author{
CURRENT WAY OF SPEAKING IN SPAIN
}

\author{
Amando de Miguel Rodríguez \\ Sociólogo, Madrid. España/Spain \\ VI Premio de Ensayo Breve Fermín Caballero \\ fontenebro@msn.com
}

\section{EL HABLA COMO USO SOCIAL}

Una cosa es el "lenguaje" propiamente dicho como objeto de estudio, análisis y perfeccionamiento por parte de filólogos, lingüistas y gramáticos. Ese enfoque suele mantener un tono prescriptivo: lo que es correcto para una buena sintaxis. El supuesto excelso de esa aproximación sería el estudio del lenguaje literario. Pero cabe otro aproche en esa incruenta batalla, el de considerar el "habla" como un uso social. Es algo parecido a describir o explicar la moda en el vestir o los hábitos alimentarios. En esos casos no hay prescripción sino observación, comparación y análisis. Lo que cabe es estudiar el lenguaje literario y las otras manifestaciones del idioma que podríamos llamar culto en contraste con las expresiones del habla popular. Por cierto, una de las peculiaridades del idioma español -si lo comparamos con el inglés- es la poca distancia que suele haber entre el lenguaje literario y el habla popular. De ahí el carácter inevitablemente realista de lo mejor de la Literatura española de todos los tiempos. O también puede entenderse el tono afectado que a veces rezuma del habla popular.

Más que el idioma español o castellano, me interesa el habla actual de los españoles, es decir, la forma en que se expresan en la vida corriente. De sobra sé que ese interés se encuentra muy extendido. Somos legión los diletantes de la lengua, como lo son los de la música. No hace falta haber pasado por el Conservatorio (hermosa palabra) para gozar de la música, como tampoco se necesita ser doctor en Filología para disfrutar de la palabra. Parece un truismo lo que digo, pero en la realidad algunos filólogos miran con suspicacia ese menester de ocuparse del habla actual de los españoles. El desdén aparece cuando la observación se detiene en los aspectos políticos del habla. Pero resulta fascinante el dialecto "politiqués", es decir, el que caracteriza a los políticos y otros personajes públicos. Al final la política (como tantas otras cosas) se resuelve en palabras. Como declama Hamlet: Words, words, words. Como escribe San Juan: In principio erat Verbum. Qué curioso, ese sonido wor y ver... indica el fluir de las voces humanas. Seguramente esa misma asociación está en gentilicios como "beréber, ibero o bárbaro". La etimología de las palabras requiere más imaginación que experimentación. 
El punto de vista del habla como uso social permite transgredir el principio corporativo de que sólo los lingüistas se deben ocupar de la lengua. Es el mismo principio por el que los economistas se reservan la exclusiva de estudiar el desarrollo económico o los teólogos son los únicos que se ocupan de analizar la religión. Pero todos esos objetos de estudio, y muchos más, son hechos sociales y permiten que el sociólogo, o el simple aficionado o curioso, se encaren con ellos. No obstante, deben acarrear el riesgo de aparecer como zurupetos; terrible cosa para una sociedad tan corporativa como la española.

Otro rasgo distintivo del idioma español es que el articulado por los españoles es sólo una parte pequeña del mundo hispanoparlante, de los que hablan o escriben ese idioma. De tal modo es así que, a pesar de su primacía histórica, el idioma español de España gusta de llamarse "castellano". No importa que, a su vez, Castilla (la región o la antigua corona) sea solo una fracción del territorio español. Lo curioso es que, salvo en Navarra, en ninguna parte de España se dice oficialmente que el español sea la "lengua propia" de los españoles o de parte de ellos. No hace falta. La consideración del "habla" como uso social nos señala que el español es el idioma común de los españoles, el único en el que se pueden entender casi todos ellos. Lejos de disolverse en algunos territorios, el hecho estadístico es que hoy es más alta que nunca la proporción de españoles que pueden entenderse en español. Tampoco se puede sostener que el español sea la "lengua del Estado", a no ser -como ahora se estila- que "Estado" sea un sustituto para obviar el término "España". Por lo menos en el habla, está claro que el español es el idioma común de los españoles, incluso de los que no quieren serlo. Esa es otra peculiaridad de algunas tribus subpirenaicas tocadas de nacionalismo.

La consideración de la lengua como "habla" permite observar otro hecho. Estamos ante una lengua viva, extraordinariamente dinámica, que evoluciona y se recompone de acuerdo con lo que exigen los nuevos tiempos. Al final, esos cambios se reflejan en la Literatura del momento. Esa evolución se dibuja a saltos, esto es, con periodos más o menos estancos y otros de intensa transformación. Incluso en el lenguaje del Quijote se puede ver que es más moderno que el de las Novelas ejemplares, en donde aparecen más arcaísmos. Precisamente el lenguaje $\tan$ arcaico que a veces emplea don Quijote, cuando "ejerce" de caballero, lo introduce el autor como objeto de mofa. Lo de "caballero" es ya parte de ese juego, pues don Quijote se deleita con arcaísmos cuando perora montado a caballo. Quizá fuera por serendipidad, pero qué gran descubrimiento el de Cervantes al plasmar que una misma persona pueda expresarse a través de distintas formas del lenguaje según las ocasiones.

Hay otro momento en el que el lenguaje español da un salto considerable. Es el que corresponde a la llamada "Generación del 98", en su definición más amplia. Es un grupo de escritores que supo incorporar muy bien el habla viva de su tiempo. Casi todos ellos podían pasar por folcloristas. Ha pasado un siglo desde aquella magnífica eclosión literaria y quizá estemos ahora en otro momento de 
rápida mutación lingüística. Ahora se percibe la poderosa influencia del inglés. El habla actual de los españoles aparece entreverada de expresiones anglicanas. Convendría recordar lo de "la lengua fue siempre compañera del imperio", que propiamente Nebrija aplicó al latín, no tanto al español. Hoy se puede predicar eso mismo del inglés ubicuo en todos los continentes. Porque el imperio americano (de los Estados Unidos) es más cultural que económico, político o militar, para desesperación de muchos artistas e intelectuales españoles que suelen ser visceralmente antiamericanos. Lo son sobre todo cuando no han podido con el idioma inglés.

La penetración del inglés en el habla de los españoles significa un enriquecimiento de nuevas realidades, como por ejemplo todo lo relacionado con la internet (palabra que todavía suele escribirse con mayúscula). Hay también una parte negativa, la invasión de locuciones traducidas del inglés que se repiten a troche y moche como muletillas. Ejemplos:

- estamos hablando (o cualquier otro presente continuo)

- yo diría

- ¿sabes?

- de alguna manera

- entre comillas (con el gesto de dibujar en el aire las comillas con los dedos)

- en este sentido

- en cualquier caso

En todos esos ejemplos, no es que las locuciones de influencia anglicana estén mal, sino que se abusa de ellas como cansinas muletillas.

$\mathrm{La}$ influencia del inglés es notoria especialmente en las personas que apenas lo chapurrean. No es solo la importación de algunas voces, sino la forma de construir las frases. Por ejemplo, se abusa del pronombre "yo", cuando la conjugación de los verbos españoles permite prescindir de ese retórico rodrigón. El pronombre se hace elegante en castellano cuando se quiere poner énfasis en el sujeto. Recordemos los famosos versos de Calderón de la Barca: "Yo sueño que estoy aquí / destas prisiones cargado". Pero en la generalidad de los casos el pronombre se elide y todos contentos. Es más austero y elegante decir "pienso que" que "yo pienso que". Claro que lo horrísono, que tanto se oye, es "yo pienso de que".

En algunos idiomas suele darse un modo distinto de hablar o de pronunciar según la clase social del hablante. Desde luego, eso es así en inglés, sobre todo en el británico. El español no acusa tanto esa diferencia, pero sí la que mantiene la localización geográfica. Por eso el idioma español admite tantas vacilaciones regionales y aun locales. Es algo que llena de satisfacción a los hablantes. La impregnación del inglés en el habla de los españoles actuales no es la única influencia exógena. Lo decisivo es que la lengua común -el castellano- coexiste con otras lenguas regionales (catalán, valenciano, balear, vasco, gallego). Aparte 
están los dos millones de extranjeros que residen en España y que hablan otras lenguas de nación. Está por ver qué va a pasar con esa babel.

Está en decadencia la palabra "región", así que no se sabe qué título se puede dar a las otras lenguas españolas que no son el castellano común. Lo de "vernáculo" no se lleva. Nadie quiere ser indígena en su tierra. Cada una de esas lenguas regionales se considera "propia" de un determinado territorio, con fronteras políticas más que lingüísticas. Lo de lengua "propia" para esos casos es un disparate conceptual, puesto que el carácter "propio" se debe aplicar a las personas, no a los territorios. Resulta un sinsentido que a un habitante típico de Requena o de Orihuela se le diga que su lengua propia es el valenciano. Pero así está en las leyes. Se acabará enseñando a los escolares que Miguel Hernández fue un poeta que no pudo escribir en valenciano porque se lo prohibieron las autoridades.

El asunto de las lenguas regionales en España es eminentemente político y polémico. La razón es que, al declararse como lenguas "propias" de ciertas regiones (llamadas curiosamente "autonomías"), los habitantes que se expresan en castellano deben admitir que su lengua es "impropia". No es una broma. Un habitante castellanoparlante de algunas regiones donde se hablan dos lenguas puede ser castigado por las autoridades. Es lo que ocurre cuando pretende expresarse en su lengua, cuando es la española, a través de los pertinentes rótulos comerciales o de la asistencia a la escuela. Las paradojas no terminan aquí. Después de los experimentos de "inmersión" educativa en los distintos idiomas regionales, la realidad es que la proporción de españoles que entienden el idioma español es más alta que nunca. Es una confirmación de que el habla, a través de los medios y de la relación personal, es más fuerte que la lengua aprendida en la escuela. Es decir, el idioma hablado domina sobre el idioma aprendido. Muchos escolares se ven "inmersos" en un idioma distinto al familiar, pero al final muchos de ellos vuelven a utilizar ese idioma familiar cuando es el castellano. También en su día los escolares estudiaron latín intensamente, pero luego lo olvidaron al no utilizarlo.

Es muy difícil averiguar cuántos son los hablantes de un idioma. Las encuestas sobre el uso de las lenguas regionales en España son muy poco válidas para determinar ese hecho. El sesgo procede del factor de deseabilidad. Simplemente es de buen tono decir que uno habla una determinada lengua regional. Otra cosa es que efectivamente la utilice en según qué círculos. Es el mismo sesgo por el que las encuestas sobre ocio nos hacen creer que existe una desmesurada afición al teatro o a los documentales científicos de la televisión.

La cuestión de las lenguas regionales es doblemente polémica porque los nacionalismos españoles suelen apoyarse en la respectiva lengua "propia" como símbolo mayor de su identidad particular. Los otros elementos definitorios tienen menos fuerza o son inapreciables (raza, religión, incluso tradiciones históricas). La prueba es que solo se alzan los nacionalismos allí donde pueden apoyarse en una 
lengua privativa, es decir, la que apenas existe fuera de la región respectiva. Allí donde esa lengua no tiene vigencia escrita, simplemente se fuerza su existencia por la vía oficial. Es el caso de las lenguas vernáculas de Asturias, Cantabria o Aragón. El empeño de los nacionalismos de todos los partidos por "normalizar" el idioma privativo significa desplazar el castellano todo lo posible. Se llega incluso a inventar neologismos para que el idioma "propio" se aleje todo lo posible del castellano omnipresente. Es inútil. El castellano preterido en los círculos oficiales se impone a través del habla, de la comunicación privada. Otra cosa es que esa forma de supervivencia contribuya al deterioro de la lengua culta.

La vitalidad del idioma español no depende de que sea "propio" de ningún territorio, ni siquiera "oficial”. ¿Es que hay una indumentaria propia u oficial de los habitantes de una nación? Es claro que no. Pues la lengua hablada por una gran parte de sus habitantes tampoco añade mucho si queda definida como "propia" u "oficial". Si se declara "propia" una lengua es para confirmar que los que la tienen por familiar van a ser los que van a mandar en el territorio correspondiente. De nuevo, "siempre la lengua fue compañera del imperio". En el caso de las lenguas regionales es un imperio sobre una gota de agua.

La pugna entre el castellano y las lenguas regionales se resuelve por el carácter de "lengua de comunicación" que tiene la lengua común de los españoles. Resulta que es también la lengua común en una veintena de países. Una "lengua de comunicación" se define por esta serie de características, que no implican un juicio de valor sino una constatación estadística:

- Se aprende masivamente por los que no la tienen como familiar.

- Deja traducir fácilmente el gentilicio con que se conoce esa lengua. Por ejemplo, el castellano es Spanish para el mundo angloparlante, pero el vascuence presiona para que sea conocido en otros idiomas como euskera. En inglés España es Spain, pero en castellano se presiona socialmente para decir Euskadi (que, por otra parte, es un neologismo) en lugar de País Vasco. para medrar.

- No necesita el carácter de lengua "propia", ni siquiera el de "oficial",

- Se emplea más allá del círculo doméstico o del referido a las tradiciones en el territorio del que es privativa.

- Se impone por la utilidad de los intercambios más que por la obligatoriedad. nacionalista.

- No sirve para identificar políticamente a una corriente que se siente

Cuantos más rasgos de esa lista tenga una lengua de comunicación, más fácil será su mantenimiento y su expansión. Cuantos menos rasgos posea, más fácil es que pertenezca al grupo de lenguas étnicas, muchas de ellas en declive o incluso en rápido trance de extinción. Surge así, una nueva paradoja. La política "normalizadora" de las lenguas españolas que no son el castellano conduce a lo contrario de lo que desean los nacionalistas, a su erosión como lenguas de relación 
habitual. En muchos otros casos se ha producido ese fenómeno de las "consecuencias no anticipadas de la acción social", al decir del sociólogo Robert K. Merton. Es una lección de humildad.

Mientras subsista el carácter de "lengua de comunicación" que tiene el castellano y de "lenguas étnicas" que poseen todas las demás españolas, el conflicto será inevitable. La única alternativa lógica (aunque difícil) para la supervivencia de las lenguas regionales en España es que logren sustituir el castellano por el inglés como lengua principal de comunicación. Es algo parecido a lo que sucedió hace un siglo en Filipinas. Es una salida que han propiciado en España algunos intelectuales nacionalistas pero hasta la fecha con poco éxito.

Uno de los rasgos más notorios del idioma español es que, a pesar de su fragmentación en una veintena de países, la forma escrita o culta es común en todos ellos. Hay variaciones mínimas, mucho menores que las que afectan al inglés o al árabe. No obstante, subsisten algunas tendencias disgregadoras. Un ejemplo es la del tuteo, la forma cada vez más corriente en el habla del español europeo, que se aleja del tratamiento de usted, típico del español americano y del canario. El tuteo se ha impuesto en los consejos de la publicidad oficial. Un cartel de la Junta de Andalucía dice: "Tú puedes parar el cambio climático: utiliza el transporte público". No se sabe qué admirar más, si el compadreo del consejo o la pretensión utópica de enlazar un suceso cósmico con una conducta personal. Un consejo de la Dirección General de Tráfico es "No podemos conducir por ti". En ese caso contrasta el plural mayestático, o simplemente irresponsable, con el tuteo confianzudo. En los anuncios publicitarios de España se utiliza cada vez más el tuteo, sobre todo si los destinatarios son los jóvenes.

Una paradoja del habla es la infinita gama de variaciones que muestra. Si el lenguaje es un código de señales, a partir de una treintena de signos, ¿por qué no se simplifica al máximo la variedad de palabras y de frases? Antes de eso ¿por qué no se unifican los idiomas y se comprimen en un tronco común las variedades dialectales? La respuesta es que el lenguaje no se hizo solo para comunicarse, sino también para confundir y engañar al interlocutor. ¿Qué mejor recurso, para esa función mendaz, que dominar la lengua mejor que el interlocutor? Sin llegar al engaño, basta con dejar las frases inconclusas o con doble sentido para despistar al interlocutor. El premio de esa técnica hay que dárselo a esta locución con la que terminan algunas parrafadas los gallegos: “¿y luego?”. No es verdad que el lenguaje sirva solo para comunicarse. Al menos en el habla está claro que también se emiten palabras para despistar o confundir al interlocutor. Lo de "hablando se entiende la gente" es gran sinsorgada. Hablando también se pelea uno. Los debates o coloquios de todo tipo no sirven para convencer al interlocutor sino para reafirmar las creencias de los intervinientes. El lenguaje se explica también como un elemento de identificación, de pertenencia a una cultura, una ideología, un grupo. En ese caso está claro que el lenguaje apunta a la diferenciación, a las variaciones que tienden al infinito. Las confrontaciones ideológicas acaban siendo 
intercambio de significados que los contendientes dan a las mismas palabras. A su vez, el habla refuerza esa tendencia disgregadora. Así pues, no hay lugar para un solo idioma internacional, sea el inglés, el esperanto, el ido o cualquier otro. Incluso dentro de un mismo lenguaje, no hay manera de que las palabras sean siempre unívocas.

Aceptemos provisionalmente la hipótesis de que las lenguas sirven para distinguirse o diferenciarse. Se comprenderá ahora lo desmesurada que es la pretensión de que en un territorio con dos lenguas (una étnica y otra de comunicación) todos sus habitantes sean perfectamente bilingües. Esa pretensión, lejos de favorecer a la lengua étnica, significa la amenaza de su erosión.

El hecho de que en España convivan diversas lenguas étnicas con una lengua de comunicación no significa que la influencia se establezca siempre desde el castellano a las otras lenguas. Las influencias son en los dos sentidos. Ejemplos de la penetración del catalán en el habla castellana de hoy:

- Generalización del "como que", muchas veces en un tono coloquial.

- Aprecio por el nuevo saludo "buen día", cuando el castellano desprendido siempre ha deseado "buenos días". El castellano posee un sentido festivo del plural (vacaciones, fiestas).

- Aceptación del horrísono impersonal "ha habido", que, por otra parte, tampoco es muy ortodoxo en catalán.

- Confusión entre "sacar y quitar", o entre "escuchar y oír".

El habla de los españoles se distingue por la abundancia de recursos retóricos. Es llamativo, por ejemplo, el tono de voz altisonante en las conversaciones, a lo que se añade el continuo acompañamiento de la gesticulación. En la vida pública se impone la palabra "actuación" (más ampulosa que "acción"). Por lo mismo se dice que los personajes públicos "escenifican" su presentación ante el público, es decir, dan forma dramática a sus parlamentos y conductas. Todo ello hace que la vida de relación tenga algo de teatrera, como si los "actores" estuvieran representando una función dramática.

La forma de hablar de los políticos hace resaltar el sentido dramatúrgico que muestra la vida pública. Por ejemplo, se abusa de la "retórica trinitaria", tan clásica, por la que se concede especial fuerza a la concatenación de tres palabras. Recuérdese el famoso recurso de "sangre, sudor y lágrimas", si bien en el original de Churchill era "sangre, fatiga, sudor y lágrimas". Pero, al repetir el recurso, se redujo a los tres elementos dichos.

Por cierto, ese juego trinitario lo practicaron algunos políticos españoles de la época republicana. Por ejemplo, Diego Martínez Barrio, con motivo de los sucesos de Casas Viejas, dijo en las Cortes: "Creo que hay algo peor que un régimen se pierda, y es que ese régimen caiga enlodado, maldecido por la Historia, entre vergüenza, lágrimas y sangres" (1933). José María Gil Robles utilizaba mucho en sus mítines el recurso de "sangre, fango y lágrimas" (1934). Estaba claro que se estaban preparando para la guerra civil. El ritmo trinitario se observa en la 
gran ventaja que suelen tener las siglas constituidas por tres letras: ETA, IRA, ONU, PIB, IVA. La ventaja fonética del castellano sobre el inglés en ese aspecto es que las siglas pueden decirse como sustantivos. Por eso mismo, es preferible recurrir al artículo (la ETA, el IRA, la ONU, etc.).

El político cultiva mucho más la forma que el contenido de sus discursos. Lo que le importa es la apariencia, quedar bien, "estar a la altura de las circunstancias", como tantas veces repiten. Los argumentos son válidos si se exhiben como el jugador de cartas muestra al final las suyas. Por eso se abusa de la expresión "encima de la mesa" para indicar cualquier movimiento en pos del ansiado "diálogo".

Aparte de "actuación y escenificación", son muchas las voces del vocabulario de la política práctica que nos llevan al sentido dramatúrgico con que se presenta la vida pública: "ámbito, entorno, escenario, espacio, marco, patético". El sentido dramatúrgico del discurso político se acentúa con la moda actual de hablar de forma intencionalmente pausada, entrecortada y repetitiva. Es una manera de hablar que recuerda el tono que tienen los profesores de dictar un texto a los alumnos. Aunque es posible que las modas pedagógicas hayan desterrado la práctica del "dictado". La mezcla de la obsesión pedagógica del lenguaje político con la influencia del inglés hace que, en el habla, se trasladen los acentos a la primera sílaba o que se acentúen los monosílabos átonos. Así, en los discursos oficiales puede oírse "lá sólidaridad" o "la alianza dé cívilizaciones". El político procura ser enfático en sus discursos y declaraciones; de esa forma cree ser más suasorio. Por otra parte, aun sin apearse del tono campanudo, el político suele recrearse en motivos del habla popular. Por ejemplo, el recurso a la muletilla "lo que es", perfectamente prescindible, pero que se puede repetir hasta la exasperación del auditorio.

No es verdad que, al hablar, cumplamos el principio económico de emplear el menor número posible de palabras y todas ellas precisas. Antes bien, el habla presenta un continuo exceso retórico, quizá para que el hablante gane tiempo o para que el interlocutor se pierda un poco. Véase, por ejemplo, la cantidad de expresiones ociosas que se forman con dos palabras reduplicativas unidas por la copulativa "y". Forman una especie de remache como si no bastara con una sola de las voces de cada dualidad.

- largo y tendido (= ampliamente).

- única y exclusivamente (= sólo).

- lo cierto y verdad (= verdaderamente).

- siempre y cuando (= con la condición de).

- lo primero y principal (= primeramente).

- al fin y a la postre (= definitivamente).

- de modo y manera (= así).

- lisa y llanamente (= claramente).

- todos y cada uno (= todos). 
La decisión de emitir dos palabras unidas por la " $y$ " en lugar de una hace que el habla sea muy florida y enfática.

A los españoles les encanta la polémica lingüística o gramatical, si las palabras significan esto o lo otro, o si se escriben de una u otra manera. Por lo que respecta a los contenidos, los hablantes no acaban de interiorizar un hecho sencillo, que muchas palabras tienen dos o más significados perfectamente legítimos. Es muy común la actitud de rechazar alguno de los posibles significados como espurio, no admitido. Es fácil suponer que esa polivalencia se resuelve muchas veces en ambivalencia y, por tanto, en confusión. Sin embargo, a menudo ese rasgo de los varios significados posibles de una palabra confiere una especial gracia a la conversación. El chiste o la situación cómica se suele derivar muchas veces de un malentendido, de que una palabra compita por dos significados.

Es claro que no se puede pensar sin palabras, aunque no haya que pronunciarlas. Al menos es así para los humanos actuales después de que surgiera el habla hace cien mil años y la escritura hace diez mil. No se puede pensar sin palabras, pero tampoco se puede jugar sin ellas. Hay pocos juegos totalmente silenciosos. Las palabras sirven para jugar con ellas porque pueden significar cosas distintas y porque nunca podremos asimilar todos sus significados. La razón es bien sencilla. Las acepciones que tienen las palabras varían con el tiempo. Por ejemplo, "álgido" fue alguna vez algo así como "lo más frío" y ahora tiende a ser "lo más caliente". Caprichos de la evolución.

El habla es un continuo fluir de palabras nuevas que llegan frescas como neologismos y de otras -los arcaísmos- que representan cosas o acciones desusadas. Da un cierto placer conservar algún arcaísmo que otro para indicar que la lengua es la que es porque la hablaron los antepasados. Un ejemplo, es muy común la expresión "dejar algo en el tintero" para indicar algo que se omite, cuando hoy ya prácticamente no disponemos de tinteros. Por lo mismo se dice "la pluma" de un escritor para indicar su capacidad literaria, cuando ya no existen plumas como utensilios para escribir. Son raras, incluso, las plumas estilográficas, que se dicen como analogía. Esa inercia de las realidades pasadas se extiende incluso al lenguaje no verbal. Para pedir al interlocutor que nos llame por teléfono podemos hacer un gesto con el dedo índice que gira alrededor de un disco. Es el remedo de cuando los números de los teléfonos se marcaban sobre un disco giratorio. Todavía se puede uno encontrar con el gesto de la mano que da vueltas a un hipotético manubrio para indicar ese mandato de "llámame por teléfono". El gesto nos retrotrae a una época, que ya casi nadie puede recordar, en la que los teléfonos requerían la fuente de energía que proporcionaba un pequeño manubrio.

Se podría asegurar que, cuanta menos precisión tenga, más interés despierta una actividad de conocimiento. Ese es el caso, por ejemplo, de la Etimología, una ciencia lingüística que se mueve por aproximaciones. Pues bien, a muchas personas les fascina indagar el origen de las palabras y de otras muchas cosas. La verdad es que la exploración etimológica suele ser muy útil para entender 
mejor la realidad a la que nos referimos. Por ejemplo, tómese la palabra "estadística". A primera vista parece derivarse de "Estado". De esa forma entendemos muy bien que tantas estadísticas sirvan a las fuerzas políticas, a los gobernantes. Pero ese origen es espurio. "Estadística" viene de "estado", que en la lengua clásica significaba lo que hoy decimos como "tabla" o "cuadro", es decir, una presentación numérica en un texto. Una estadística no es más que una condensación de palabras.

Cuando no se puede hablar o las palabras no sirven de mucho, se gesticula, se comunica uno con el cuerpo, la indumentaria, los símbolos de todo tipo. Aunque la secuencia cronológica quizá fuera al revés. Primero los homínidos "hablarían" con gestos y luego con gruñidos y al final con voces articuladas. La prueba es que en la raíz de muchas palabras en distintos idiomas hay una voz natural, lo que llamamos onomatopeya. Por ejemplo, la raíz ur significa tanto ciudad como agua en muchos idiomas asiáticos y europeos, incluido el vascuence y seguramente los primitivos idiomas ibéricos. $U r$ es el sonido del agua que fluye. No es casualidad que las "urbes" se hayan levantado junto a corrientes de agua dulce. $U r$ fue la mítica ciudad de Abraham, junto al Éufrates. La urbe por antonomasia es Roma, junto al Tíber.

Naturalmente, nunca averiguaremos qué es lo que impulsa a nuestros antepasados homínidos a pasar del gesto y el gemido a la palabra. Podemos imaginar que ese trascendental paso se dio cuando aquellos homínidos necesitaron engañar a sus semejantes. Tal urgencia se derivaba de un conjunto de extraños placeres del espíritu: hacerse con el mando, figurar, presumir, distinguirse, vengarse, acentuar la desigualdad. En cuyo caso desde el principio se pudo ver que el lenguaje articulado es una manera de complicar las relaciones sociales.

\section{Breve currículo:}

\section{Amando de Miguel Rodríguez}

Catedrático de Sociología de la Universidad Complutense. Realizó estudios de postgrado en la Universidad de Columbia y ha sido profesor visitante en las de Yale y Florida. Ha publicado más de un centenar de libros y miles de artículos. Los títulos de los últimos libros son: Escritos contra corriente. El otro sentir de la sociedad española, Hacían una pareja estupenda..., Los españoles y la religión, Entre los dos siglos, Nuestro mundo no es de este reino, La lengua viva. Polémicas apasionadas sobre el idioma español, Sociología del Quijote, El arte de envejecer, Servir al Rey. Recuerdo de la mili 1938-2001, Secuestro prolongado. Ha sido galardonado con los premios de ensayo: Espasa (1988), Jovellanos (2001), Miguel Espinosa (2003) y Premio de Cuentos Café "El Pícaro" (Toledo, 2004). Es colaborador habitual de la cadena COPE, los periódicos La Razón, El Economista, Libertad Digital y la revista La Ilustración liberal. Es miembro del Consejo Económico y Social de la Comunidad de Madrid. 